\title{
A NEW PATTERN MOUTH STICK
}

\author{
By M. A. Frankel, B.D.S. (U. London), J. HawkesFord, B.D.S. (U. London), \\ and J. Simonson, M.A.O.T. \\ Dental Department, Stoke Mandeville Hospital, Aylesbury, England
}

Mouth sticks have probably been used by limbless and paralysed patients for as long as civilised mankind has existed. One of the first documented references in the use of a mouth stick is most likely the one written by William Dampier who was the vicar in the Parish of Coggeshill in the I850s. He recorded in his book 'The souls triumph amid the bodies wreck' the life and works of one of his parishioners, a John Carter, who had sustained injury and subsequent paraplegia by falling 40 feet from a tree, whilst in an alcoholic state searching for rooks. No doubt Dampier felt this a just reward as Carter's accident had occurred on a Sunday and he had preferred the ale house to church. Carter remained totally paralysed in all four limbs for the remaining is years he survived. Carter's equipment was very simple with a drawing board which rested on his chest and a simple form of mouth stick (fig. I). His achievements however were remarkable as can be seen from the following example (fig. 2).

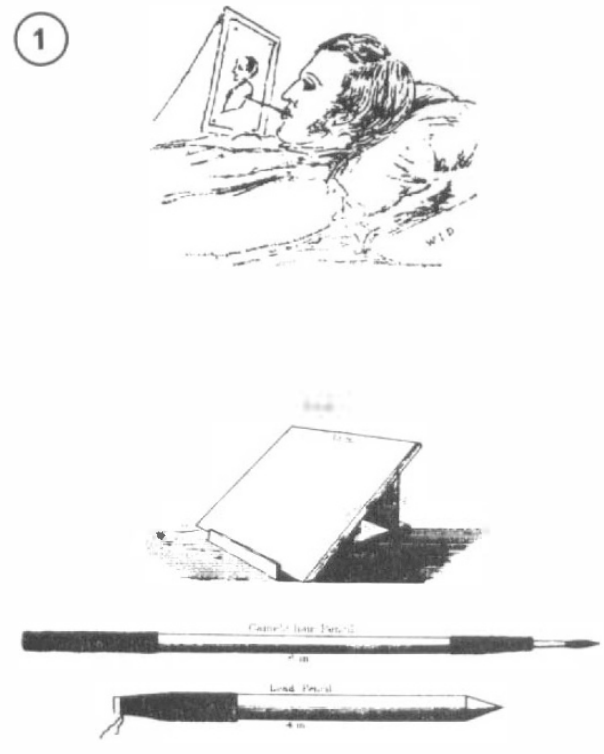

FIG. I

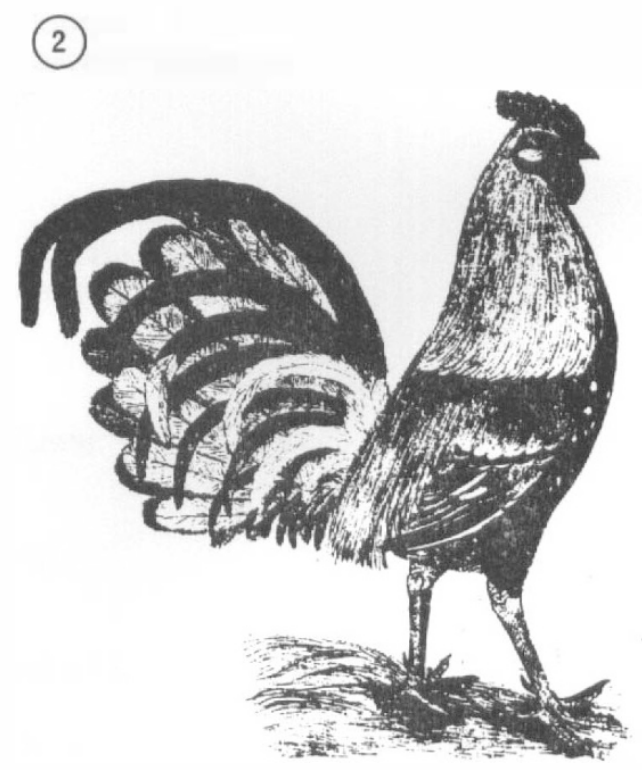

FIG. 2

Spinal cord lesions complete below $\mathrm{C}_{4}$ result in a tetraplegic state. Occupational therapy is a very important part of the treatment in these patients and because of the paralysis of all their limbs the only therapy available is that which utilises the movements of the neck and oral musculature.

The previous pattern of mouth stick which had been used satisfactorily for 

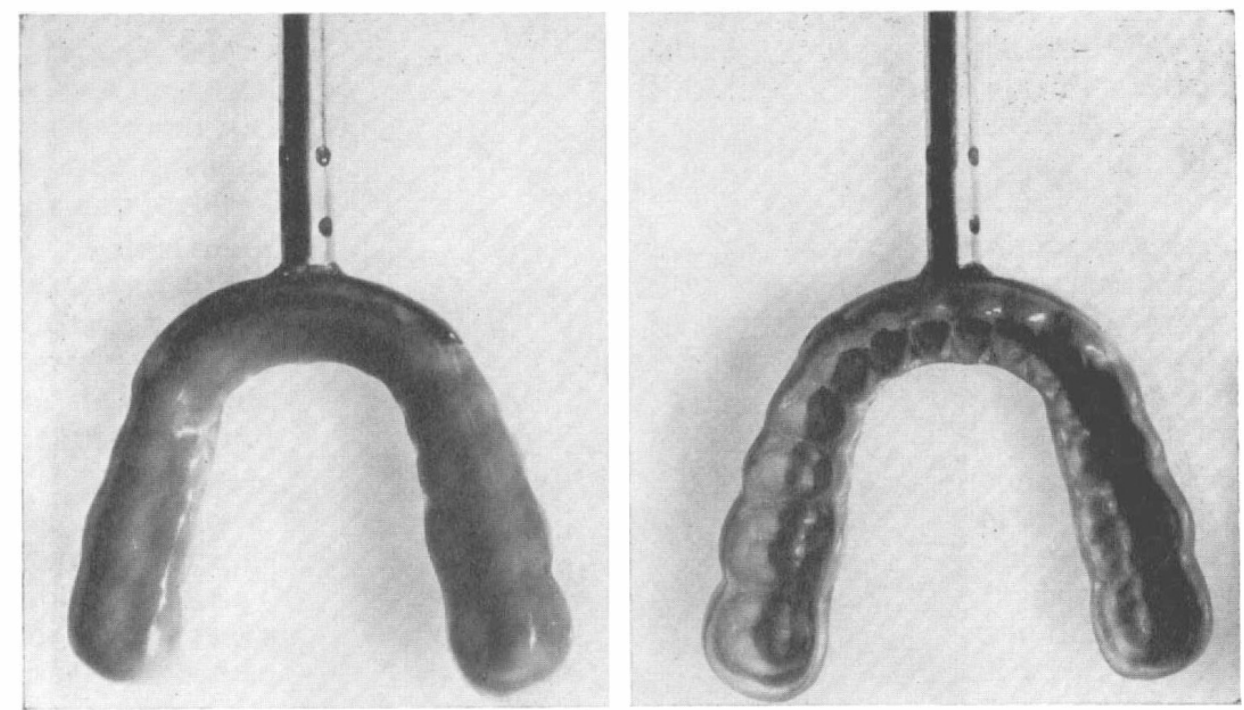

FIG. 3

many years at Stoke Mandeville was a flat piece of acrylic resin attached to an aluminium rod; this was maintained in position by the patient biting of the acrylic continuously. It enabled the patient to carry out occupational therapy but a great deal of muscular effort was required to keep it in place. The patient was also unable to talk or eat during its use (fig. 3).

The aims in the construction of the new Stoke Mandeville Hospital pattern mouth stick were as follows:

I. To enable the patient to speak whilst in use.

2. To allow the stick to be in place for a period of up to two to three hours without fatigue.

3. To produce a light and easily fitted comfortable mouth stick.

For these requirements an attachment to the mandibular teeth was required which would enable gravity to help maintain the stick in position and thus eliminate the need for clenching of the maxillary and mandibular teeth to maintain it in position. Thus the new pattern is also constructed of acrylic and is basically a close fitting acrylic splint with a soft lining; this is attached to the aluminium projection stick (fig. 4).

\section{Method of Construction}

I. Mandibular and maxillary impressions are taken with an alginate material.

2. Plaster casts are made and trimmed by the technician along the gingival margin to allow the finished mouth stick to fit closely to the teeth.

3. Two wax patterns are laid down, one overlying the other.

4. The anterior portion of the wax pattern is thickened to allow for the later attachment of the aluminium rod. The model, together with the pattern, is invested and by customary dental procedures an acrylic splint replaces the wax pattern. The soft lining material Molloplast ' $\mathrm{B}$ ' is then inserted 


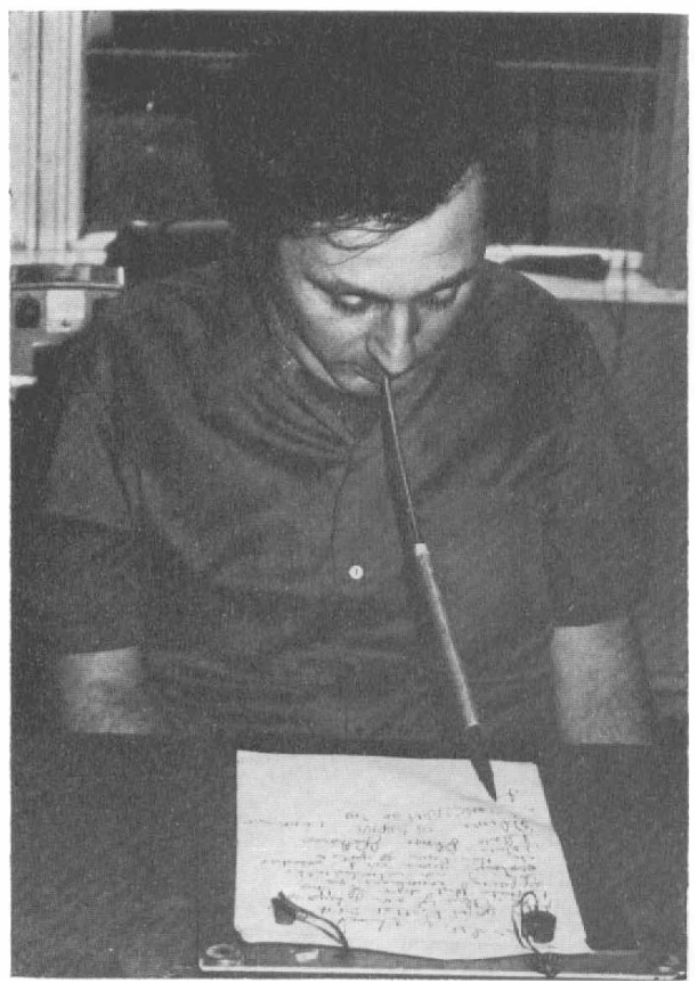

FIG. 4

and processed; this gives a sponge rubber finish attached to the teeth aspect of the acrylic splint.

After processing has been completed the cap splint together with the soft lining is polished and the occlusion is adjusted by articulating the maxillary model with the mandibular model with the cap splint in place.

The aluminum projection is attached to the cap splint. As quite a large amount of force will be developed at this point, it is important that a strong firm attachment is made, but this cannot be bulky as it would interfere with the lip musculature.

A strip of victoria plate metal through which a $I_{4}^{1}$ inch screw is placed is attached to the cap splint with acrylic resin and the aluminium projection rod is attached to this screw.

Modifications. In the construction of this mouth stick it has been assumed that the patient has all teeth present. The partially edentulous patient presents only a slight problem. Chrome cobalt partial dentures should be fitted and then the patient is treated as that described for a fully dentate patient, the impressions being made with the partial denture in place.

For the fully edentulous patient the construction of the appliance is modified. A close fitting denture which occludes with the upper denture is constructed and to this an aluminium projection rod is attached. This appliance then takes the 
place of the normal lower denture when the mouth stick is required. This type of patient, however, is rare, as most tetraplegics are younger patients who have most of their teeth present. The fully dentate patient is better able to accommodate a mouth stick. It is, therefore, very important that these tetraplegic patients who rely upon oral aids for their occupational therapy have meticulous oral hygiene care and regular dental treatment to maintain a healthy dentition.

Adjustments. The requirements in the length of the aluminium projection rod is varied and by incorporating two different gauges of aluminium tubing it is possible to adjust the length of the projection bar by sliding the two tubes together. These can be secured with a screw. This, however, tends to weaken the stick and increase the weight, we therefore normally try to provide several mouth sticks if different lengths of projection rods are required.

Adaptations. As this oral appliance can be used in numerous occupations, adaptations have been made for the attachments to the end of the stick to be altered for reading books, typing, using calculators and dialling the telephone. A rubber cashier's thimble can be attached to the end of the projection with acrylic. For playing chess, a small hook-type attachment can be attached to the end of the projection bar and for painting and writing a specially designed pen holder is attached.

The Cost. Although the mouth stick is quite a simple design, like most dental appliances it is a precision appliance. The materials cost is in the region of five pounds sterling. The surgeon spends approximately 30 minutes in taking impressions and fitting the appliance.

The technician spends approximately three and a half hours in the construction of the appliance. This would result in an overall cost of around 25 pounds sterling.

Training in the Use of the Mouth Stick. This depends upon the patient and his motivation. In the occupational therapy department the patient has normally become accustomed to using the bite stick within four weeks and can manage by this time to read books, and newspapers, play a game of chess or draughts and use a calculating machine. A much greater length of time is required to develop the art of writing, but with perseverence it is possible to train patients to write and sign letters.

\section{SUMMARY}

The motivation for the severely handicapped tetraplegic patient in using the mouth stick is quite considerable as through this simple oral aid they are able to carry out small jobs and be involved in social activities. We feel that this modified pattern mouth stick fulfils the aims which we require of it.

Acknowledgements. We should like to thank the Departments of Oral Surgery, Occupational Therapy and Photography for their help in preparing this paper, and especially Mr. J. J. McClurg for his help in constructing the appliance.

\section{REFERENCES}

Dampier, William James (1875). A Memoir of fohn Carter. New ed. Simpkin, Marshall \& Co., London. 